\title{
Effect of sub-Zero Treatment on Ageing of Aluminium Composite
}

\author{
Ahmet Taşkesen, Sinan Aksöz, and A. Tamer Özdemir
}

\begin{abstract}
In this study, B4C reinforced 7075 Al composites were fabricated by cold and hot pressing of $\mathrm{Al}, \mathrm{Cu}, \mathrm{Zn}$ and $\mathrm{Mg}$ elemental powders. Two different reinforcement rates $(10 \%$ and $15 \%$ ) were used for the composites. In order to examine the structural and mechanical properties, different sub-zero and ageing processes were applied to the composites. Sub-zero and stepped ageing treatments were applied after solutionizing at $470{ }^{\circ} \mathrm{C}$ for different time periods. It was found that hardness of the composite was substantially increased and micro structure was changed. Findings show that, general strength of the material significantly increased particularly after solutionization process.
\end{abstract}

Index Terms-B4C, aluminium composite, sub-zero treatment, ageing.

\section{INTRODUCTION}

Recently, there has been a substantial increase in the studies on Aluminum (Al) and its alloys due to especially its lower weight to strength ratio [1]-[3]. Lower density, good formability, ability to reach higher hardness values [4] and to increase its mechanical properties by additional processes also played a fundamental role in improving the usage areas of $\mathrm{Al}$ alloys [5]. Inclusion of magnesium in $\mathrm{Al}$ alloys results in an improved corrosion resistant as well as weightstrength ratio [6]. Moreover, good wettability properties have a favorable influence on microstructure of the alloy [7]. In addition to various ceramic particulates [8], [9], $\mathrm{B}_{4} \mathrm{C}$ is also used in the design of the metal matrix composites (MMC) [6], [10] and a better mechanical strength can be obtained [11]. Because of its unique strength and corrosion resistance, Al7075 alloys, which have been used in aviation and space industry, are both used commercially and become the center of interest for research and development Works. In the current studies on age hardenable Al 7075alloys [12], [13], micro structure of the alloy can be improved, and advanced mechanical properties can also be obtained [14]. On the other hand, subzero process techniques have been partially used and studied in order to improve the overall material structure and properties [15]-[17]. Studies on the sub-zero treatments of $\mathrm{Al}$ and its alloys have been gradually increased [14], [18].

The aim of this study was to search the capability to increase the strength of Al7075 composite as far as possible. For this reason, composites having two different rates of $\mathrm{B}_{4} \mathrm{C}(10 \%, 15 \%)$ particle reinforcements were fabricated by

Manuscript received August 12, 2016; revised January 3, 2017.

The authors are with Gazi University, 06500 Besevler, Ankara, Turkey (e-mail: taskesen.a@gmail.com, sinanaksoz@gazi.edut.tr, 2007atam@gmail.com). liquid phase sintering. Then, different sub-zero and ageing processes were applied. The change in the structural and mechanical properties was examined.

\section{METHOD}

\section{A. Ball Milling and Pressing}

In order to achieve $\mathrm{B}_{4} \mathrm{C}$ reinforced $\mathrm{Al} 7075$ based composite structure, $\mathrm{B}_{4} \mathrm{C}$ powders having $20 \mu \mathrm{m}$ average size, Al powders having $20 \mu \mathrm{m}$ average size, $\mathrm{Zn}$ powders having $10 \mu \mathrm{m}$ average size and $\mathrm{Cu}$ powders having $15 \mu \mathrm{m}$ average size were mixed for 2 hours by using a mechanical grinder. Then, the mixture was cold pressed into the mold under $25 \mathrm{MPa}$. Later, in order to fill the voids between metal and ceramic powders with zinc, the furnace temperature was kept $540{ }^{\circ} \mathrm{C}$ and composite specimens were fabricated for a half hour. Finally, the mold was kept inside the furnace until $250{ }^{\circ} \mathrm{C}$ furnace temperature and then placed in the open air to complete the cooling. This method was similar to the fabrication route used by previous researchers [6], [19]-[22].

Different reinforcement rates of $\mathrm{B}_{4} \mathrm{C}$ inclusions were performed for the purpose of determining the influence of $\mathrm{B}_{4} \mathrm{C}$ addition on the mechanical properties of $\mathrm{Al} 7075+\mathrm{B}_{4} \mathrm{C}$ composite (Table I).

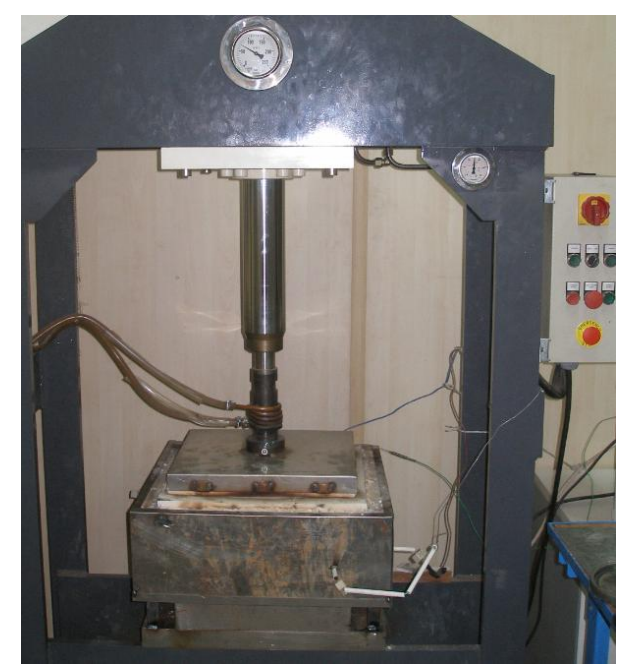

Fig. 1. Photograph of test apparatus for composite fabrication.

TABLE I: CHEMICAL COMPOSITIONS OF FABRICATED COMPOSITES, WT.\%

\begin{tabular}{|l|c|c|c|c|c|}
\cline { 2 - 6 } \multicolumn{1}{c|}{} & $\mathrm{Al}$ & $\mathrm{B}_{4} \mathrm{C}$ & $\mathrm{Zn}$ & $\mathrm{Cu}$ & $\mathrm{Mg}$ \\
\hline $10 \% \mathrm{MMC}$ & 79 & 10 & 5 & 3,5 & 2,5 \\
\hline $15 \% \mathrm{MMC}$ & 74 & 15 & 5 & 3,5 & 2,5 \\
\hline
\end{tabular}

\section{B. Metallographic Investigations}

Test specimens were cut into slices and polished with 
sandpaper in order to make suitable for metallographic and micro hardness examinations. General characteristic of the structure was obtained with the analysis of Scanning Electron Microscope (SEM) and Energy Dispersive X-ray Spectroscopy (EDS).

\section{Sub-Zero and Ageing Treatments}

After applying solutioning treatments at different time periods, the specimens were subjected to sub zero cooling process at $-140^{\circ} \mathrm{C}$, and then stepped ageing treatment was applied (Fig. 2a) and Fig. 2b)). Furthermore, conventional T6 ageing treatment was performed for 25 hours prior to sub zero treatment in order to get the effect of sub zero treatment on the hardness of the specimens (Fig. 2c). In Fig. 2a), the specimens, which were firstly subjected to solutioning process at $470{ }^{\circ} \mathrm{C}$ for 12 hours, were treated to sub zero process at $140^{\circ} \mathrm{C}$ for 24 hours, and then they were aged at $120{ }^{\circ} \mathrm{C}$ for every 3 hours. Quenching process was applied after every 3 hours for the stepped ageing process. In Fig. 2b), hardness values were obtained with the similar aging treatments from the test specimen solutionized at 470 ${ }^{\circ} \mathrm{C}$ for 2 hours. 3 hour stepped ageing process was applied for the determination of the maximum hardness value. Test specimens were subjected to 9 hours ageing process after the sub zero cooling process since the maximum hardness value was obtained for 9 hour-ageing treatment, as seen from Fig. 2b. In addition, in order to see the influence of sub zero treatment on the ageing process without taking into account the solutioning time, a typical ageing process, which was generally applied to Al7075 alloys, was also applied to the test specimens (Fig. 2c)).

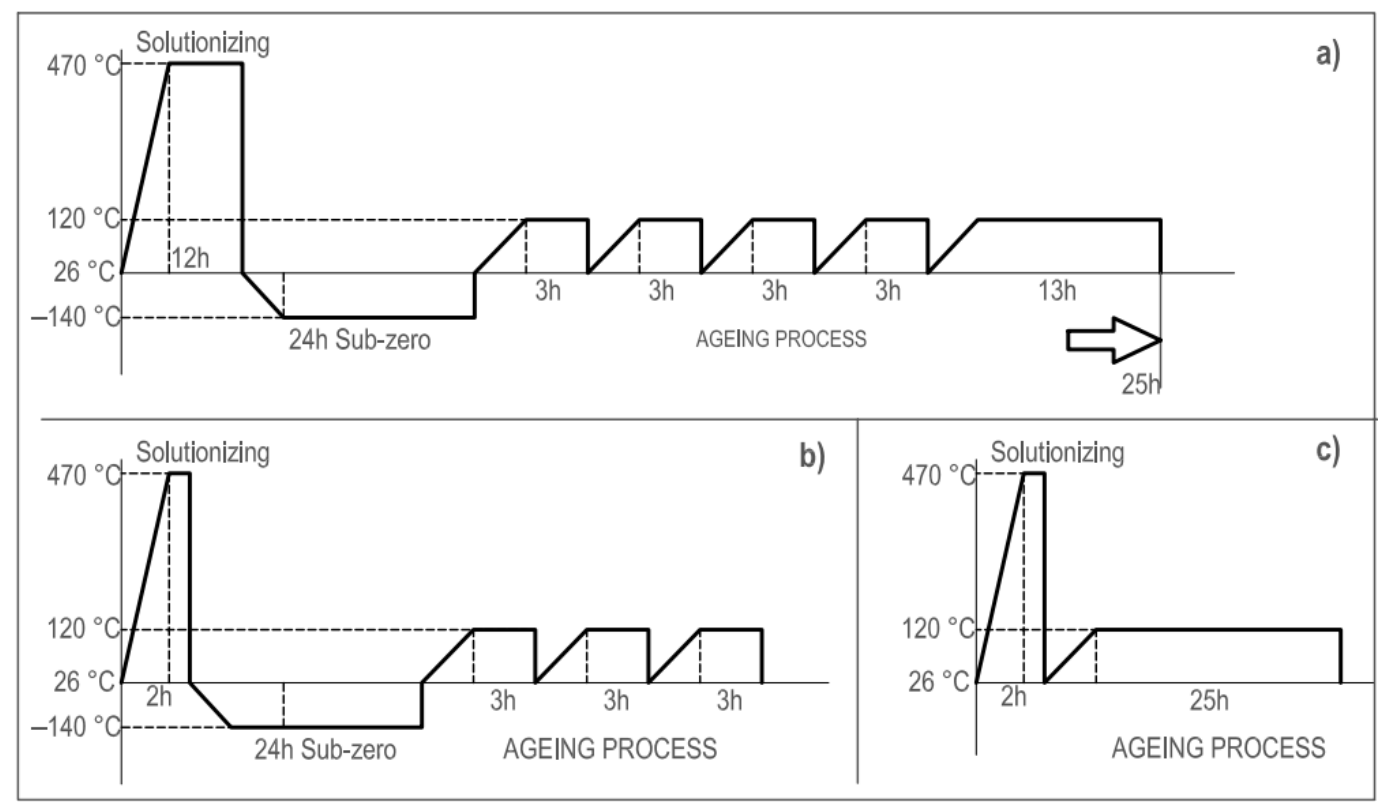

Fig. 2. Diagrams of Applied Sub-Zero and Ageing Treatment a) $470{ }^{\circ} \mathrm{C}+12$ hours solutionizing +24 hours Sub-Zero + ageing at $120^{\circ} \mathrm{C}$ with 3 hours intervals, b) $470{ }^{\circ} \mathrm{C}+2$ hours solutionizing +24 hours Sub-Zero + ageing at $120^{\circ} \mathrm{C}$ with 3 hours intervals, c) Typical ageing process for $7075 \mathrm{Al}$ alloys

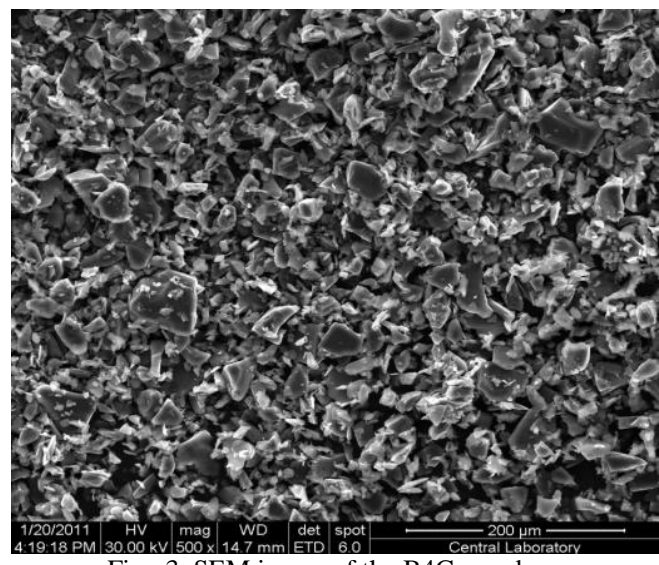

Fig. 3. SEM image of the B4C powders.

\section{Hardness and Density Measurements}

After the sub zero cooling and different ageing processes, micro and macro hardness values of the composites were measured. Micro hardness values were used and analyzed since approximately same values were measured for micro and macro hardnesses. Measurements were carried out with SHIMADZU micro hardness device under $10 \mathrm{~g}$ and $1 \mathrm{~kg}$

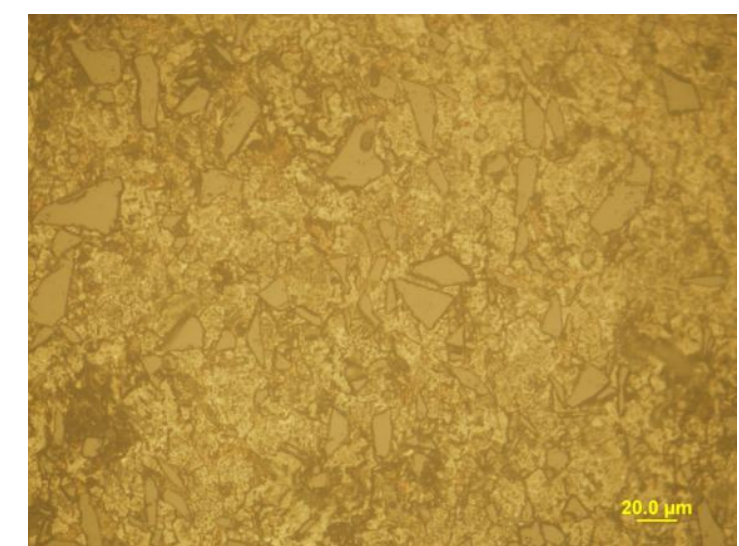

Fig. 4. Optical microscope views of $15 \%$ B4Cp reinforced MMCs produced by liquid phase sintering method

loads.

\section{E. Micro Structure of Composite Material and Its Properties}

It could be observed from the morphology presented in Fig. 3 that $\mathrm{B}_{4} \mathrm{C}$ ceramic powders are angular and agglomerated. Optical microscope images of the hot pressed powders show that a homogeneous distribution and high 
density can be seen due to the effect of pressing and liquid phase sintering (Fig. 4).

\section{RESULTS AND DISCUSSION}

Existent literature studies stated that subzero heat treatment could be applied especially for steel materials and that this treatment enhanced the strength in particular toughness, corrosion resistance and fatigue properties [15][17], [23]. Heat treated material properties can be significantly affected by subzero level as well as the rate of temperature decreasing and holding time of lowest temperature [23]-[26]. Subzero process is theoretically based upon 3rd law of thermodynamics [23]. As it is known, any material kept at $0^{\circ} \mathrm{K}$ for a long time reaches an ideal equilibrium condition and get rid of structural defects and all internal stress and strains. Furthermore, atomic distances become smaller, particle shape and structure refines, general micro structure gradually becomes uniform and entropy of the material approaches to zero as far as possible. Ultimately, in addition to above mentioned properties, the super arranged microstructure can have high friction and wear resistance as well as high resilience properties [23].

In the first stage of this study, the test specimens, solutionized at $470^{\circ} \mathrm{C}$ for 12 hours, were subjected to a cooling process at $-140^{\circ} \mathrm{C}$ for 24 hours and then they were gradually aged (Fig. 2a)). In Fig. 5, hardness values of the test specimens, which were solutionized at $470{ }^{\circ} \mathrm{C}$ for 12 hours and subjected to sub zero cooling treatment, can be seen depending on the ageing time. Zero (0) time on the horizontal axis means that the specimens were solutionized at $470^{\circ} \mathrm{C}$ for 12 hours and then they were subjected to only

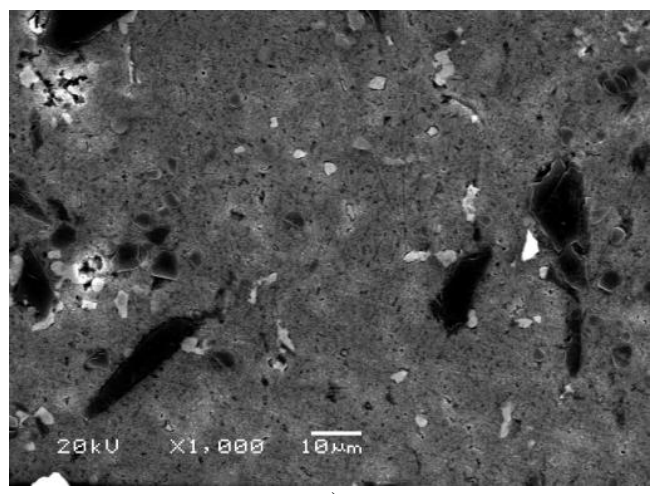

a)

6. SEM micrographs of $10 \% \mathrm{~B} 4 \mathrm{C}$ reinforced structure with and without sub-zero treatment.

a) 12 hours solutionizing at $470{ }^{\circ} \mathrm{C}+$ water quenching +25 hours ageing at $120^{\circ} \mathrm{C}$.

b) 12 hours solutionizing at $470{ }^{\circ} \mathrm{C}+$ sub-zero treatment +25 hours ageing at $120{ }^{\circ} \mathrm{C}$

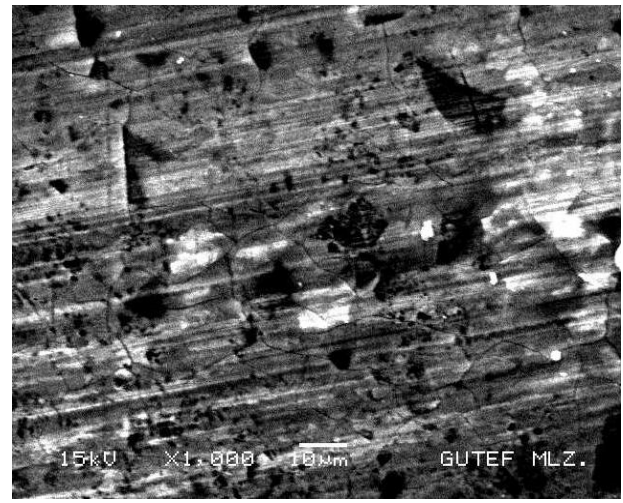

Fig. 7. Micro structures of $15 \% \mathrm{~B} 4 \mathrm{C}$ reinforced composites after 12 hours solutionizing at $470{ }^{\circ} \mathrm{C}+$ sub-zero treatment +25 hours ageing at $120^{\circ} \mathrm{C}$. sub zero cooling treatment at $-140^{\circ} \mathrm{C}$ for 24 hours. Maximum hardness value of the specimens was obtained after approximately 9-hour ageing process. Moreover, hardness seriously increased with increasing $\mathrm{B}_{4} \mathrm{C}$ reinforcement rate. SEM images of $10 \% \mathrm{~B} 4 \mathrm{C}$ reinforced composite structure homogenized at the same conditions, with sub zero treatment and without sub zero treatment, are presented in Fig. 6. From the microscopic examinations, it was observed that cracks were formed at the structure (Fig. 6b) and also that micro cracks increased with more than $15 \% \mathrm{~B} 4 \mathrm{C}$ reinforcement rate (Fig. 7).

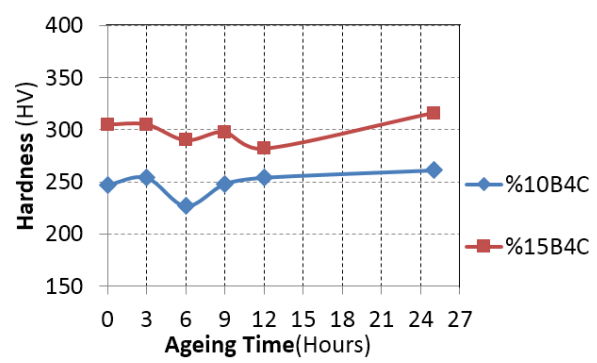

Fig. 5. The effect of $470{ }^{\circ} \mathrm{C}+12$ hours solutionizing +24 hours Sub-Zero ageing treatments on the hardness.

Past studies pointed out that subzero cooling rate might be important and also that micro cracks can be observed with sudden temperature variations [27]. In this work, some cracks were observed as seen in Fig. 6 and Fig. 7. Although these cracks were caused from the subzero treatment, they increased with increasing reinforcement element. Because of this, it would appear inevitable that at least the cracks were formed at some locations of the structure due to very hard nature of the composite material.
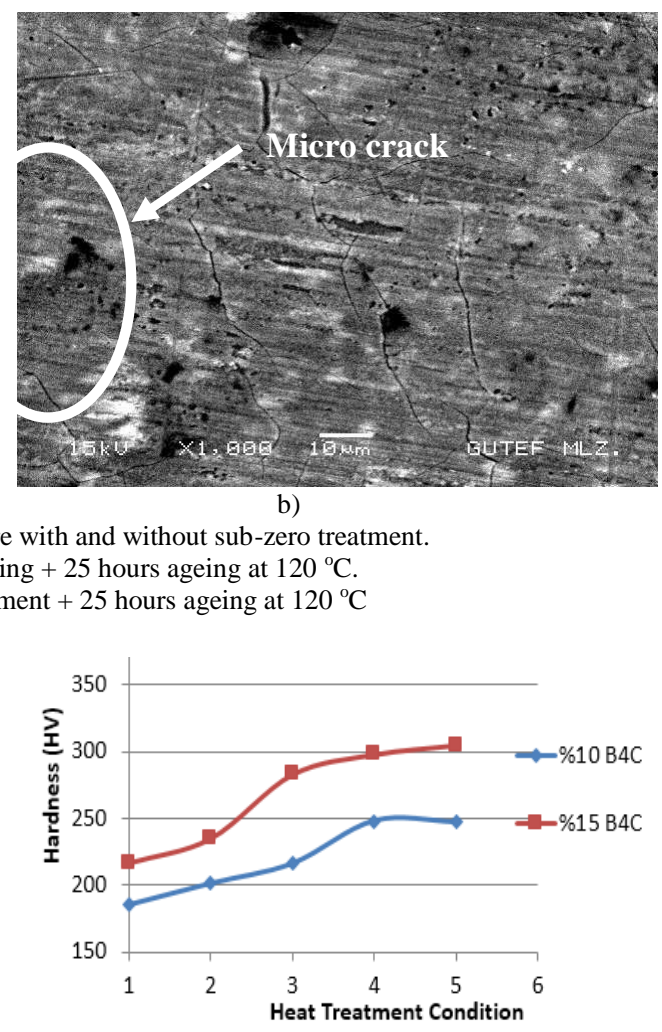

$1=$ Untreated specimen (No heat treatment was applied) $2=$ Solutionized at $470{ }^{\circ} \mathrm{C}$ for $2 \mathrm{~h}+25 \mathrm{~h}$ aging process $3=$ Solutionized at $470{ }^{\circ} \mathrm{C}$ for $2 \mathrm{~h}+$ subzero cooling $+9 \mathrm{~h}$ aging process $4=$ Solutionized at $470{ }^{\circ} \mathrm{C}$ for $12 \mathrm{~h}+$ subzero cooling $+9 \mathrm{~h}$ aging process $5=$ Solutionized at $470{ }^{\circ} \mathrm{C}$ for $2 \mathrm{~h}+$ subzero cooling process Fig. 8. The effect of heat treatments on hardness. 
In order to see the effect of subzero process on the hardness directly, hardness values of untreated specimen and the specimens treated to different applications (for example; solutioned at $470{ }^{\circ} \mathrm{C}$ for 12 hours and 2 hours) were compared. By looking into the hardness values presented in Fig. 8, increasing the solutionizing time caused the alpha $(\alpha)$ phase in the structure become more homogenous and thus the hardness increased more specifically. Moreover, the typical characteristic of the Fig. 8 is that the hardness values obtained from solutionizing + subzero cooling processes is quite higher than the hardness values obtained from classical ageing process.

From the general EDS analysis given in Fig. 9 and Fig. 10 , it could be seen that there was an expected B and C density in the structure.

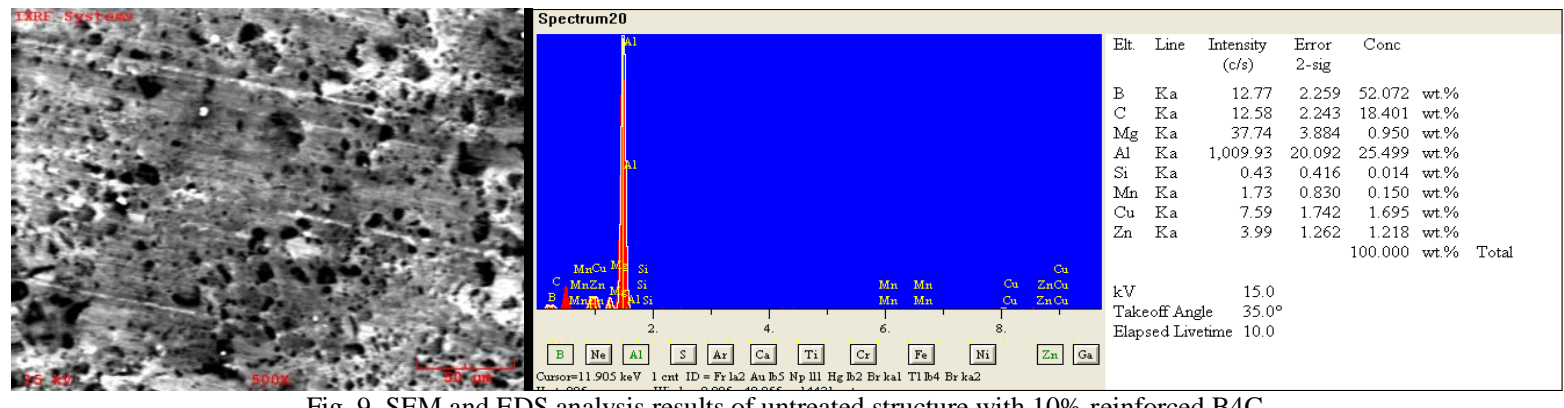

Fig. 9. SEM and EDS analysis results of untreated structure with $10 \%$ reinforced B4C.

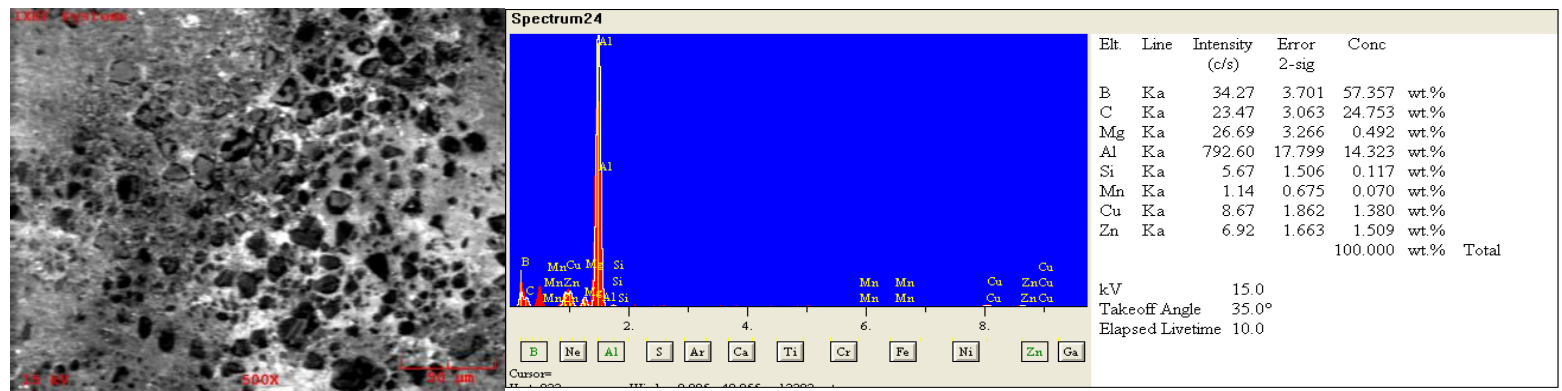

Fig. 10. SEM and EDS analysis results of $10 \%$ reinforced $\mathrm{B} 4 \mathrm{C}$ composite heat treated as; 12 hours solutionizing at $470{ }^{\circ} \mathrm{C}+$ sub-zero +25 hours ageing at $120{ }^{\circ} \mathrm{C}$.

\section{CONCLUSIONS}

In this study, the effect of cryogenic treatment on the ageing behavior of $\mathrm{B}_{4} \mathrm{C}$ reinforced 7075 aluminium alloy was investigated at the ageing temperature of $120^{\circ} \mathrm{C}$. Properties of B4C reinforced A17075 composite improved by applying subzero treatments at different stages. More homogenous structure was obtained. Moreover, it was found that general strength of the material significantly increased. Findings show that, particularly after solutionization, cryogenic treatment before ageing yielded high hardness values.

\section{REFERENCES}

[1] B. Bostan, "Examination of Al4C3 Formation after Mechanically Alloying and Extrusion," J Faculty Eng Architec Gazi Univ, vol. 23, no. 2, pp. $343-8,2008$

[2] S. Aksoz, A. T. Ozdemir, and B. Bostan, "Alloyed aa2014 aluminium powders synthesized with carbon and determined properties," $J$ Faculty Eng Architec Gazi Univ, vol. 27, no. 1, pp. 109-15, 2012

[3] U. Gokmen and M. Turker, "Effect of Al2O3 addition on the foamability behaviour of aluminum and alumix 231 based metallic foam," J Faculty Eng Architec Gazi Univ, vol. 27, no. 3, pp. 651-8, 2012

[4] Y. Li, Y. H. Zhao,V. Ortalan, W. Liu, Z. H. Zhang, R. G. Vogt et al., "Investigation of aluminum-based nanocomposites with ultra-high strength," Mater Sci Eng A-Struct Mater Prop MicrostrProces, vol. 527, no. $1-2$, pp. 305-16, 2009

[5] I. Ciftci, M. Turker, and U. Seker, "Evaluation of tool wear when machining SiCp-reinforced Al-2014 alloy matrix composites," MaterDes, vol. 25, no. 3, pp. 251-5, 2004

[6] A. Taskesen and K. Kutukde, "Analysis and optimization of drilling parameters for tool wear and hole dimensional accuracy in B4C reinforced Al-alloy," Trans Nonfer Met SocChina, vol. 23, no. 9, pp. 2524-36, 2013.
[7] A. Contreras, C. Angeles-Chavez, O. Flores, and R. Perez, "Structural, morphological and interfacial characterization of $\mathrm{Al}-\mathrm{Mg} / \mathrm{TiC}$ composites," Mater Charac, vol. 58, no. 8-9, pp. 685-693, 2007.

[8] A. E. Karantzalis, S. Wyatt, and A. R. Kennedy, "The mechanical properties of Al-TiC metal matrix composites fabricated by a fluxcasting technique," Mater Sci Eng A-Struct Mater Prop MicrostrProces, vol. 237, no. 2, pp. 20020-6, 1997.

[9] H. L. Wang, R. Zhang, X. Hu, C. A. Wang, and Y. Huan, "Characterization of a powder metallurgy $\mathrm{SiC} / \mathrm{Cu}-\mathrm{Al}$ composite," J Mater Process Tech, vol. 197, no. 1-3, pp.43-8, 2008.

[10] M. Khakbiz and F. Akhlaghi, "Synthesis and structural characterization of Al-B4C nano-composite powders by mechanical alloying," J Alloys Compounds, vol. 479, no. 1-2, pp. 3343-41, 2009.

[11] R. Ipek, "Adhesive wear behaviour of B4C and SiC reinforced 4147 Al matrix composites (Al/B4C-A1/SiC)," J Mater Process Tech, vol. 162, pp. 71-5, 2005.

[12] J. F. Li, Z. W. Peng, C. X. Li, Z. Q. Jia,W. J. Chen, and Z. Q. Zheng, "Mechanical properties, corrosion behaviors and microstructures of 7075 aluminium alloy with various aging treatments," Trans Nonfer Met SocChina, vol. 18, no. 4, pp.755-62, 2008.

[13] T. J. Harrison, B. R. Crawford, M. Janardhana, and G. Clark, "Differing microstructural properties of 7075-T6 sheet and 7075 T651 extruded aluminium alloy," in Proc. 11th International Conference on the Mechanical Behavior of Materials, 2011, pp. 3117-3121.

[14] S. K. Panigrahi and R. Jayaganthan, "Development of ultrafine grained high strength age hardenable Al 7075 alloy by cryorolling,' MaterDes, vol. 32, no. 6, pp. 3150-60, 2011.

[15] R. P. Reed and M. Golda, "Cryogenic composite supports: A review of strap and strut properties," Cryogenics, vol. 37, no. 5, pp. 233-50, 1997.

[16] A. Bensely, A. Prabhakaran, D. M. Lal, and G. Nagarajan, "Enhancing the wear resistance of case carburized steel (En 353) by cryogenic treatment," Cryogenics, vol. 45, no. 12, pp.747-754, 2005.

[17] J. D. Darwin, D. M. Lal, and G. Nagarajan, "Optimization of cryogenic treatment to maximize the wear resistance of $18 \% \mathrm{Cr}$ martensitic stainless steel by Taguchi method," J Mater Process Tech, vol. 195, no. 1-3, pp. 241-247, 2008. 
[18] A. L. Woodcraft, "Predicting the thermal conductivity of aluminium alloys in the cryogenic to room temperature range," Cryogenics, vol. 45 , no. 6 , pp. 421-31, 2005.

[19] A. Taskesen and K. Kutukde, "Optimization of the Drilling Parameters for the Cutting Forces in B4c-Reinforced Al-7xxx-Series Alloys Based on the Taguchi Method," Materiali in Tehnologije, vol. 47, no. 2, pp. 169-76, 2013

[20] A. Taşkesen and K. Kütükde, "Experimental investigation and multiobjective analysis on drilling of boron carbide reinforced metal matrix composites using grey relational analysis," Measurement: JInt Meast Confed, vol. 47, no. 1, pp. 321-330, 2014.

[21] A. Acir,Y. Turgut, M. Übeyli, M. Günay and U. Şeker, "A study on the cutting force in milling of boron carbide particle reinforced aluminum composite," Sci Eng CompMater, vol. 16, no. 3, pp. 187 195, 2009.

[22] B. S. Yilbas, S. Khan, K. Raza, O. Keles, M. Ubeyli, T. Demir et al., "Laser cutting of $7050 \mathrm{Al}$ alloy reinforced with Al2O3 and B4C composites," Int J Adv Manufac Tech, vol. 50, no. 1-4, pp. 185-93, 2010.

[23] P. I. Patil and R. G. Tated, "Comparison of effects of cryogenic treatment on different types of steels: A Review," International Journal of Computer Applications, no. 9, pp. 1-21, 2012.
[24] D. N. Collins and J. Dormer, "Deep cryogenic treatment of a D2 coldwork tool steel," Heat Treat Met, vol. 24, no. 3, pp. 71-4, 1997.

[25] D. Yun, X. P. Lin, and H. S. Xiao, "Deep cryogenic treatment of high-speed steel and its mechanism," Heat Treat Met, vol. 25, no. 3, pp. $55-59,1998$.

[26] D. M. Lal, S. Renganarayanan, and A. Kalanidhi, "Cryogenic treatment to augment wear resistance of tool and die steels," Cryogenics, vol. 41, no. 3, pp. 149-55, 2001

[27] N. S. Kalsi, R. Sehgal, and V. S. Sharma, "Cryogenic treatment of tool materials: A Review," Mater Manufac Proces, vol. 25, no. 10, pp. 1077-100, 2010.

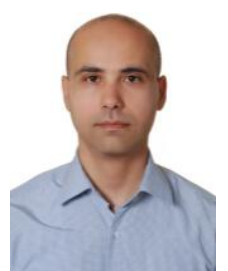

Ahmet Taskesen received his BS from the Department of Mechanical Engineering at Istanbul Aydin University, Ankara, Turkey and his $\mathrm{PhD}$ degree in mechanical education from Gazi University, Ankara, Turkey. $\mathrm{He}$ is currently an Associate Professor in the Department of Industrial Design Engineering at Gazi University, Turkey. 